\title{
Effect of OPG gene mutation on protein expression and biological activity in osteoporosis
}

\author{
SHUHUI QIN ${ }^{1}$, QIUPING ZHANG ${ }^{2}$ and LI ZHANG $^{3}$ \\ Departments of ${ }^{1}$ Orthopedics, ${ }^{2}$ Urinary Surgery and ${ }^{3}$ Endocrinology, The Third Hospital \\ of Hebei Medical University, Shijiazhuang, Hebei 050051, P.R. China
}

Received March 14, 2017; Accepted June 19, 2017

DOI: $10.3892 /$ etm.2017.4712

\begin{abstract}
The effect of an osteoprotegerin (OPG) gene mutation was investigated on its protein expression and biological activity in osteoporosis. The pcDNA3.0-OPG plasmid or wild-type plasmid were transfected into HEK293 cells. Osteoclast tartrate-resistant acid phosphatase (TRAP) staining and counting were then performed, and the expression of genes related to osteoclast differentiation and activation were measured by RT-PCR. The wild-type or mutant-type OPG at concentrations of $0,10,20,50$ and $100 \mathrm{ng} / \mathrm{ml}$ were added respectively to RAW264.7 cells and incubated for $24 \mathrm{~h}$. The viability of cells treated with the wild-type and mutant-type OPG at a concentration of $100 \mathrm{ng} / \mathrm{ml}$ was still over $99 \%$, which indicated that the wild-type and mutant-type OPG at this concentration had no cytotoxic effect on RAW264.7 cells. The number of TRAP-positive cells decreased with increasing concentration of wild-type or mutant-type OPG. At the concentrations of 20,50 and $100 \mathrm{ng} / \mathrm{ml}$, the inhibitory effect of wild-type OPG was significantly higher than that of mutant-type OPG $(\mathrm{p}<0.05)$. Both mutant-type and wild-type OPG inhibited the bone resorption activity of osteoclasts, and the inhibitory effect of wild-type OPG was significantly higher than that of mutant-type OPG at the concentrations of 20,50 and $100 \mathrm{ng} / \mathrm{ml}(\mathrm{p}<0.05)$. The levels of TRAP and RANK mRNA in the wild-type OPG treatment group were significantly lower than those in the control group, while the levels of TRAP and RANK mRNA in the mutant-type OPG treatment group were significantly lower than those in the wild-type group $(p<0.05)$. The genetic mutation did not affect the protein expression levels of OPG, but inhibited the normal activity of OPG.
\end{abstract}

Correspondence to: Dr Shuhui Qin, Department of Orthopedics, The Third Hospital of Hebei Medical University, 139 Ziqiang Road, Qiaoxi, Shijiazhuang, Hebei 050051, P.R. China

E-mail: qh6g11@163.com

Key words: osteoporosis, gene mutation, polymorphism

\section{Introduction}

Osteoporosis is a multi-gene disease. It has been shown that polymorphisms in the osteoprotegerin (OPG) gene are closely related to its occurrence. Because of the anti-osteoclast activity of OPG, it has become a candidate gene for the treatment of osteoporosis (1-3). At present, many studies have shown that polymorphisms in the OPG gene promoter and introns primarily involve the sites 163A-G, 209G-A, 245T-G, 889C-T, 950T-C, 1181G-C, and 6890A-C. A previous study found that 163,209, 245 and 1181 site polymorphisms are associated with lower bone mineral density (BMD) or bone fracture, among which, the correlation of the 245 site with the pathological changes is the largest. In contrast, the 889 , 950 and 6890 site polymorphisms are not associated with osteoporosis (4). Additionally, Japanese scholars found that the T-C polymorphism at the 223 site upstream of the OPG transcription start region is related to lower BMD (5). Another study reported that the $445 \mathrm{C}-\mathrm{T}$ polymorphism is related to Paget bone disease. During our study, we identified the genetic polymorphism, g.27563G $>$ A, within the fifth exon of the OPG gene by created restriction site-polymerase chain reaction (CRS-PCR). The potential relationship between this genetic polymorphism and both BMD and osteoporosis was analyzed. The results showed that there was a significant correlation between BMD, osteoporosis, and the genetic polymorphism in Chinese menopausal women. The female BMD associated with the GG genotype was significantly higher than that of the GA and AA genotypes. Therefore, the A-allele was a risk factor for BMD and osteoporosis. However, the specific association between OPG gene polymorphisms and osteoporosis remains unclear.

\section{Materials and methods}

Experimental instruments. Electronic micro-balance (Changsha Xiangping Science and Technology Development Co.,Ltd., Changsha, China); ice maker (Sanyo Electric Co.,Ltd., Moriguchi, Japan); $-70^{\circ} \mathrm{C}$ ultra-low temperature freezer (Forma Scientific, Inc., Marietta, OH, USA); thermostat-controlled water-bath (Ningbo Xinzhi Biotechnology Co., Ltd., Ningbo, China); oscillation mixing device (Shanghai Huayun Analytical Instrument Co., Ltd., Shanghai, China); cryogenic supercentrifuge (DuPont, Wilmington, DE, USA); table concentrator 
(Barnstead International Co., Ltd., Boston, MA, USA); UV spectrophotometer (Hitachi, Tokyo, Japan); agarose gel electrophoresis apparatus (Beijing Liuyi Instrument Factory, Beijing, China); UV gel imaging system (Bio-Rad, Hercules, CA, USA); DNA Engine PCR instrument (University of Leicester, London, UK); clean bench (Beijing Semiconductor Equipment Factory, Beijing, China); $\mathrm{CO}_{2}$ incubator (Thermo Electron Corp., Waltham, MA, USA).

Experimental materials. Human embryonic kidney (HEK)293 cells were purchased from American Type Culture Collection (ATCC, Manassas, VA, USA), and cultured in Dulbecco's modified Eagle's medium (DMEM) containing 10\% fetal bovine serum (FBS) to maintain adherent growth of cells.

RAW264.7 macrophages were from ATCC, and cultured in DMEM (containing 10\% FBS, 2 mmol/1 L-glutamine, $100 \mathrm{IU} / \mathrm{ml}$ penicillin, and $100 \mu \mathrm{g} / \mathrm{ml}$ streptomycin), under $5 \% \mathrm{CO}_{2}, 37^{\circ} \mathrm{C}$, and saturated humidity. Culture medium was changed every two days. Adherent cells were digested and subcultured when they reached $80-90 \%$ confluence.

Reagents. Lipofectamine 2000 and $\alpha$-minimal essential medium ( $\alpha-\mathrm{MEM}$ ) (both from Invitrogen, Carlsbad, CA, USA); Fast Mutagenesis system (Beijing TransGen Biotech Co., Ltd., Beijing, China); TRIzol reagent (Invitrogen); MTT cell proliferation assay kit (Nanjing Kaiji Biology Company, Nanjing, China); PCR kit (Beijing TransGen Biotech Co., Ltd.).

Construction of the mutant-type plasmid. The pcDNA3.0-OPG plasmid (wild-type, GG type) was synthesized and provided by Kangwei Century Co. (Beijing, China). The mutant-type plasmid (GA type) was obtained with the fast site-directed mutagenesis kit (Fast Mutagenesis system). The PCR site-directed mutagenesis method was provided by Beijing TransGen Biotech Co., Ltd. The primers were designed according to the primer design principles of the Fast Mutagenesis system, and all primers were synthesized by Invitrogen Biological Technology Co., Ltd. (Shanghai, China).

Cell transfection. The wild-type OPG expression vector and mutant-type OPG expression vector were transfected into HEK293 cells as follows: i) HEK293 cells were seeded in 24-well plates, with $2 \times 10^{4}$ cells per well; ii) Lipofectamine 2000 reagent diluted with medium, was added to each well and left to stand for $10 \mathrm{~min}$ at room temperature; iii) the wild-type OPG expression vector or mutant-type OPG expression vector were added, followed by addition of an appropriate amount of medium. Cells were then left to stand for $10 \mathrm{~min}$ at room temperature; and iv) cells were then left to incubate at $5 \% \mathrm{CO}_{2}$ and $37^{\circ} \mathrm{C}$ for $5 \mathrm{~h}$, after which the medium was replaced with fresh complete medium. Cells were then left to incubate for $36-48 \mathrm{~h}$.

RNA extraction. A total of $0.4 \mathrm{ml}$ TRIzol reagent was added to harvested cells. The samples were mixed and left to stand at room temperature for $5 \mathrm{~min}$. Chloroform (1/5 of the volume of TRIzol) was added, mixed evenly, and left to stand for $5 \mathrm{~min}$ at room temperature. Subsequently, the solution was centrifuged at low temperature for $15 \mathrm{~min}$ at $12,000 \mathrm{x} \mathrm{g}$. The supernatants were collected and transferred to clean centrifuge tubes. Equal volumes of isopropanol were then added, mixed evenly, and incubated for $10 \mathrm{~min}$ at room temperature. Subsequently, the solutions were centrifuged at low temperature for $15 \mathrm{~min}$ at $12,000 \mathrm{x}$ g. The supernatants were discarded. Equal volumes of $75 \%$ ethanol were added to the centrifuge tubes and mixed evenly. The solutions were centrifuged at low temperature for $5 \mathrm{~min}$ at $12,000 \mathrm{x}$. The supernatants were discarded, and the precipitates were dissolved in diethyl pyrocarbonate (DEPC)-treated water.

Reverse transcription. The reagents were added according to the following proportions, and solutions were mixed evenly. Subsequently, reverse transcription reaction was started.

10X RT Buffer, $1.5 \mu \mathrm{l}$; $10 \mathrm{mM}$ dNTPs, $1.5 \mu \mathrm{l}$; RNase Inhibitor (20 U/ $\mu \mathrm{l}), 0.2 \mu \mathrm{l}$; 5x RT Primer, $3 \mu \mathrm{l}$; RNA samples, $5 \mu \mathrm{l}$; Multiscribe ${ }^{\mathrm{TM}}$ RT enzyme $(50 \mathrm{U} / \mu \mathrm{l}), 1 \mu \mathrm{l}$; DEPC $\mathrm{H}_{2} \mathrm{O}$, $5.5 \mu \mathrm{l}$. The thermal profile was as follows: $16^{\circ} \mathrm{C}$ for $30 \mathrm{~min}$, $42^{\circ} \mathrm{C}$ for $30 \mathrm{~min}, 85^{\circ} \mathrm{C}$ for $5 \mathrm{~min}$, and $4^{\circ} \mathrm{C}$ for $5 \mathrm{~min}$.

$q R T-P C R$. The expression of OPG in cells was measured by RT-PCR. The reaction system was as follows: $2 \mathrm{x}$ TaqMan PCR Master Mix, $10 \mu \mathrm{l}$; 10x TaqMan Probe/Primer Mix, $2 \mu \mathrm{l}$; cDNA template, $1 \mu \mathrm{l}$; DEPC $\mathrm{H}_{2} \mathrm{O}, 7 \mu \mathrm{l}$. The total volume was $20 \mu \mathrm{l}$.

The thermal profile was as follows: $94^{\circ} \mathrm{C}$ for $10 \mathrm{~min}$, $94^{\circ} \mathrm{C}$ for $20 \mathrm{sec}$, and $60^{\circ} \mathrm{C}$ for $1 \mathrm{~min}$, for a total of 40 cycles. Fluorescence quantitative PCR data were analyzed by the $2^{-\Delta \Delta \mathrm{Cq}}$ method.

Total protein extraction. Total cellular protein was extracted. Cells under healthy growth conditions were washed three times in phosphate-buffered saline (PBS) to remove floating dead cells. The cultured cells were then transferred to centrifuge tubes, and centrifuged for $5 \mathrm{~min}$ at $500 \mathrm{x} \mathrm{g}$. Cell precipitates were then collected. Subsequently, a suitable amount of RIPA buffer was added, mixed evenly with cells, and placed at $4^{\circ} \mathrm{C}$ for $20 \mathrm{~min}$. During mixing, cells were constantly shaken slightly to ensure complete lysis of cells. The solution was then centrifuged for $20 \mathrm{~min}$ at $10,500 \mathrm{x} \mathrm{g}$ and $4^{\circ} \mathrm{C}$. The supernatants were collected and stored at $-80^{\circ} \mathrm{C}$ for preservation.

Western blot analysis. The protein content in samples was determined with a BCA protein quantitative kit according to the manufacturer's instructions. The final protein concentration was adjusted to $5 \mu \mathrm{g} / \mu 1$. Suitable amounts of sample buffer were added to protein samples obtained by the above steps. Samples were then boiled for 5 min to fully denature proteins. After cooling, samples were loaded in the wells of gels for SDS-PAGE. A pre-stained marker was used to accurately determine the size of proteins. The voltage was $100 \mathrm{~V}$ and the separation time was $90 \mathrm{~min}$. When all markers were fully separated and the bromophenol blue moved to the bottom of gels, the gels were removed and the marker was carefully identified. The location of the target protein in the gel was determined according to the molecular weight of the target protein. A piece of gel containing the target protein was then cut with a blade. The length and width of the gel were measured, then two pieces of filter paper and PVDF membrane of corresponding size were cut and stacked to prepare a 'sandwich'. The bubbles between the layers of the sandwich were expelled using a glass rod. The splint was placed in the 
transfer apparatus. Ice cubes and transfer buffer were added to the tank, the transfer apparatus was placed in an ice bath, and protein transfer was started. The current was $220 \mathrm{~mA}$, and the time of transfer was $1.5 \mathrm{~h}$. After transfer, the gel was stained with Coomassie Brilliant Blue dye to observe protein residues. Membranes were removed, washed with PBST solution, and a small angle in the top left corner was cut as a mark on the front and back. Next, membranes were placed in PBST solution containing 5\% skimmed milk powder and blocked for $1.5 \mathrm{~h}$. The blocking solution was then discarded. Membranes were placed in a flat plate containing PBST solution and rinsed 5 times with shaking on the table concentrator for more than $25 \mathrm{~min}$. Membranes were then placed in clean flat plates, and the anti-OPG/ $\beta$-actin primary antibody (1:1,000 dilution) diluted in PBST solution containing 5\% skimmed milk powder was added dropwise to membranes. A layer of preservative film was used to cover membranes, and they were incubated at $4^{\circ} \mathrm{C}$ overnight. After the primary antibody was collected, a suitable amount of PBST solution was added to flat plates. Plates were placed on the table concentrator for shock cleaning for $5 \mathrm{~min}$, for a total of five times. Membranes were placed in clean flat plates, and the secondary antibody (1:1,000 dilution) diluted in PBST solution was added dropwise to membranes. A layer of preservative film was used to cover the membranes, and they were allowed to incubate at room temperature for $2 \mathrm{~h}$. After the secondary antibody was removed, a suitable volume of PBST solution was added to the flat plates. The plates were placed on the table concentrator for shock cleaning for $5 \mathrm{~min}$, for a total of five times. ECL solution was added to membranes for signal development. Subsequently, the membranes were placed in an instrument for acquiring photographs.

Detecting cell viability by MTT assay. The wild-type and mutant-type OPG proteins were purified by affinity chromatography. RAW264.7 cells were resuspended in $\alpha$-MEM medium (containing 10\% FBS, 2 mmol/l L-glutamine, $100 \mathrm{IU} / \mathrm{ml}$ penicillin, and $100 \mu \mathrm{g} / \mathrm{ml}$ streptomycin), and seeded in 96-well cell culture plates. Subsequently, the cells were cultured at $5 \% \mathrm{CO}_{2}, 37^{\circ} \mathrm{C}$, and saturated humidity for $24 \mathrm{~h}$. Next, cells continued to be cultured in serum-free $\alpha$-MEM medium for $48 \mathrm{~h}$. The wild-type or mutant-type OPG protein at concentrations of $0,10,20,50$ and $100 \mathrm{ng} / \mathrm{ml}$ were respectively added to the appropriate cells. The cells continued to incubate for $24 \mathrm{~h}$. Next, the medium was discarded and cells were washed three times in PBS. DMEM containing $0.05 \mathrm{mg} / \mathrm{ml}$ MTT was added to each group of cells and they were incubated at $37^{\circ} \mathrm{C}$ for $4 \mathrm{~h}$. The supernatant was discarded and $150 \mu \mathrm{l}$ DMSO was added to each well. Shock incubation was performed for $10 \mathrm{~min}$. Next, the absorbance value at $570 \mathrm{~nm}$ was measured.

Osteoclast tartrate-resistant acid phosphatase (TRAP) staining and counting. RAW264.7 cells were re-suspended in $\alpha$-MEM medium (containing 10\% FBS, 2 mmol/1 L-glutamine, $100 \mathrm{IU} / \mathrm{ml}$ penicillin, and $100 \mu \mathrm{g} / \mathrm{ml}$ streptomycin), and seeded in 96-well cell culture plates. After incubation for $24 \mathrm{~h}$, the medium was replaced with serum-free $\alpha$-MEM containing macrophage colony-stimulating factor (M-CSF) $(25 \mathrm{ng} / \mathrm{ml})$ and receptor activator of nuclear factor- $\kappa \mathrm{B}$ ligand (RANKL) $(30 \mathrm{ng} / \mathrm{ml})$, followed by incubation for $48 \mathrm{~h}$. The wild-type or mutant-type OPG proteins at concentrations of $0,10,20$,
50 , and $100 \mathrm{ng} / \mathrm{ml}$ were respectively added to the appropriate cells and were incubated for 3 days. After incubation, TRAP staining was performed for each group of cells. The amount of TRAP-positive cells in each group was counted for statistical analysis.

Detection of bovine cortical bone slice resorption lacuna. RAW264.7 cells were re-suspended in $\alpha$-MEM medium (containing 10\% FBS, 2 mmol/l L-glutamine, $100 \mathrm{IU} / \mathrm{ml}$ penicillin, and $100 \mu \mathrm{g} / \mathrm{ml}$ streptomycin), and seeded in 48-well cell culture plates. After incubation for $24 \mathrm{~h}$, the medium was replaced with serum-free $\alpha$-MEM medium containing M-CSF (25 ng/ml) and RANKL (30 ng/ml), and incubated for $48 \mathrm{~h}$. The wild-type or mutant-type OPG proteins at concentrations of $0,10,20,50$ and $100 \mathrm{ng} / \mathrm{ml}$ were respectively added to appropriate cells and incubated for 3 days. After incubation, bovine cortical bone slices were taken out of the medium and cleaned by distilled water. Next, bone slice resorption lacuna were observed and photographed with an XL30-ESEM, and the bone resorption lacuna area in each group was compared.

Measurement of the expression of genes related to osteoclast differentiation and activation by RT-PCR. RAW264.7 cells were re-suspended in $\alpha$-MEM medium (containing $10 \% \mathrm{FBS}$, $2 \mathrm{mmol} / \mathrm{l} \mathrm{L}$-glutamine, $100 \mathrm{IU} / \mathrm{ml}$ penicillin, and $100 \mu \mathrm{g} / \mathrm{ml}$ streptomycin), and seeded in 6-well cell culture plates. After incubation for $24 \mathrm{~h}$, the medium was replaced with serum-free $\alpha$-MEM medium containing M-CSF $(25 \mathrm{ng} / \mathrm{ml})$ and RANKL $(30 \mathrm{ng} / \mathrm{ml})$, and incubated for $48 \mathrm{~h}$. The wild-type or mutant-type OPG proteins at a concentration of $100 \mathrm{ng} / \mathrm{ml}$ were added to the appropriate cells and incubated for $30 \mathrm{~min}$. After incubation, the cells were collected and RNA was extracted. Subsequently, the mRNA levels of the marker genes, TRAP and RANK, under osteoclast differentiation were measured by RT-PCR.

Statistical analysis. All experiments were repeated three times. Data are presented as mean \pm standard deviation of three independent experiments. GraphPad 5.0 software (GraphPad Software, Inc., La Jolla, CA, USA) was used for statistical analyses. ANOVA was used for comparisons of data. $\mathrm{p}<0.05$ was considered statistically significant.

\section{Results}

Effect of OPG gene mutation on OPG $\mathrm{mRNA}$ and protein expression. To investigate the effect of the genetic mutation on OPG mRNA and protein expression, we used site-directed mutagenesis in vitro to construct the mutant-type OPG expression plasmid for stable transfection in HEK293 cells. Wild-type and mutant-type OPG mRNA and protein expression levels were determined by real-time semi-quantitative PCR and western blot analysis, respectively. As shown in Fig. 1, the expression of OPG mRNA and protein in cells transfected with the OPG expression plasmid was increased. However, the mutation had no effect on OPG mRNA and protein expression levels in HEK293 cells. Therefore, we concluded that this mutation did not affect the expression of OPG.

The effect of OPG gene mutation on cell viability. The wild-type or mutant-type OPG at concentrations of $0,10,20$, 
A

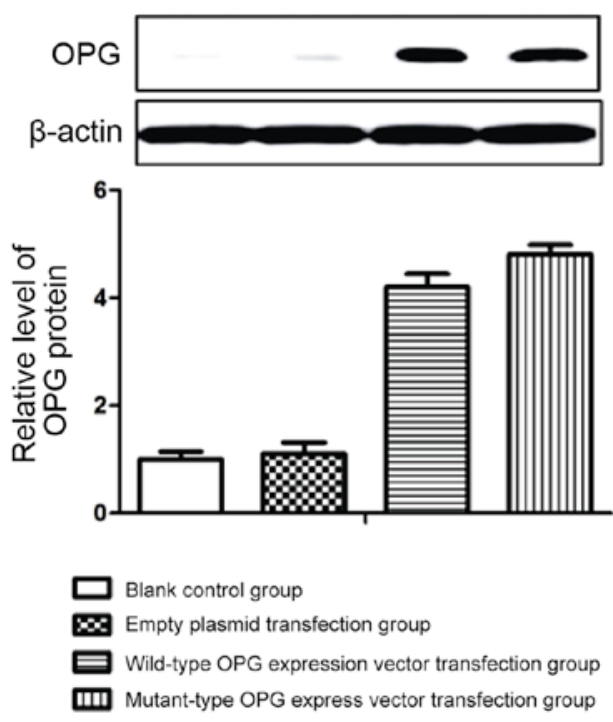

B

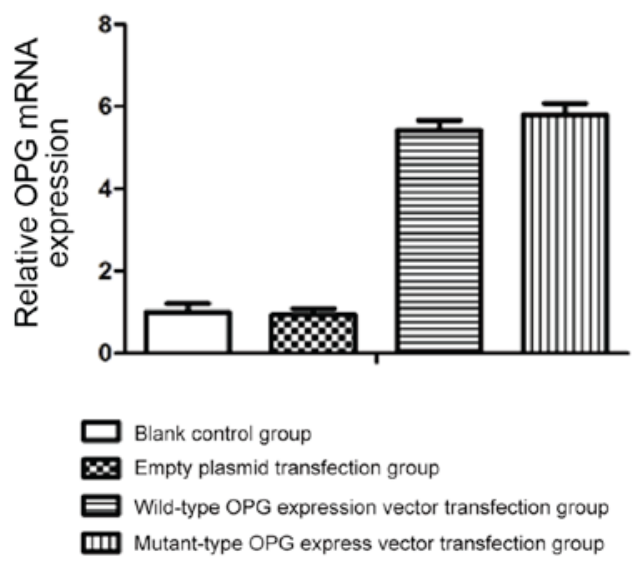

Figure 1. OPG mRNA and protein expression levels. (A) Relative expression level of OPG protein; (B) relative expression level of OPG mRNA. OPG, osteoprotegerin.
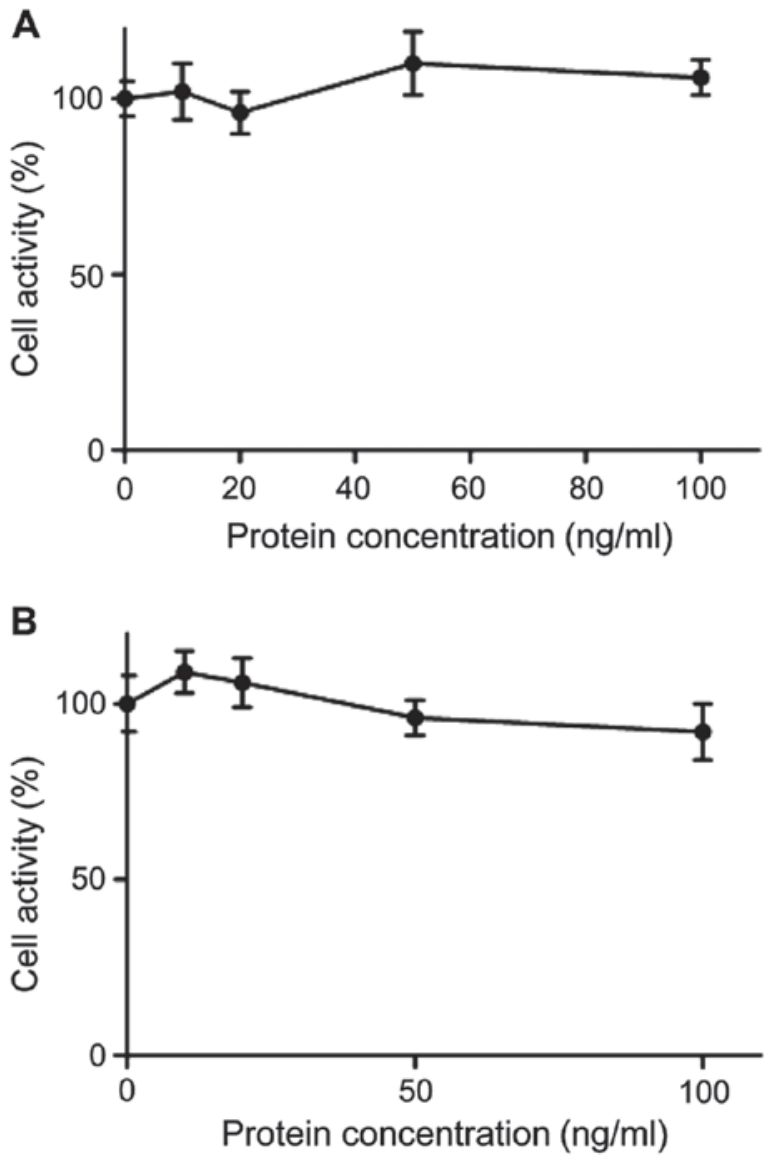

Figure 2. Effect of OPG on cell viability. (A) Effect of wild-type OPG on cell viability; (B) effect of mutant-type OPG on cell viability. OPG, osteoprotegerin

50 and $100 \mathrm{ng} / \mathrm{ml}$ were respectively added to RAW264.7 cells and incubated for $24 \mathrm{~h}$. Next, the effect of OPG on RAW264.7 cell viability was determined by MTT assay. As shown in Fig. 2, the viability of cells treated with the wild-type and mutant-type OPG at $100 \mathrm{ng} / \mathrm{ml}$ was still over $99 \%$, which

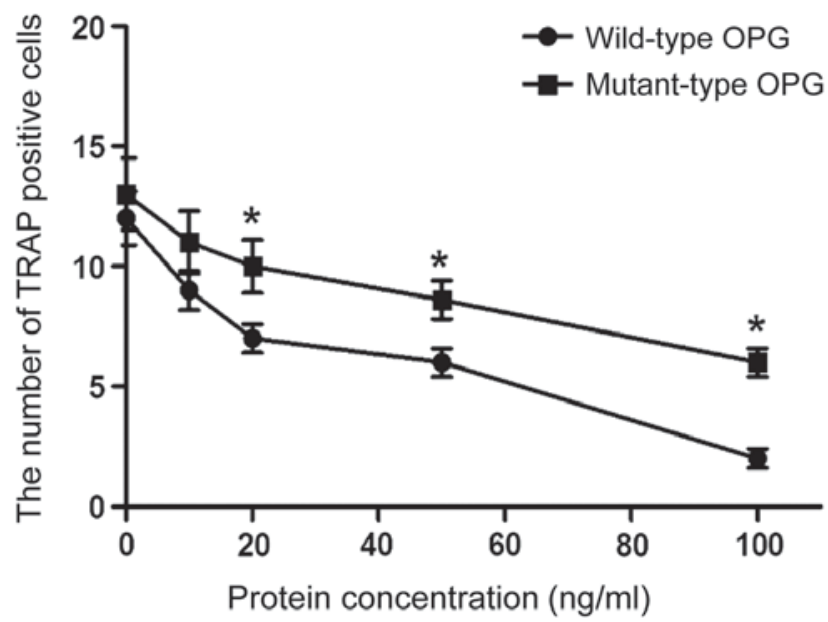

Figure 3. Inhibitory effect of OPG on osteoclast bone differentiation. "Statistical significance when compared with the wild-type OPG group, $\mathrm{p}<0.05$. OPG, osteoprotegerin.

indicated that the wild-type and mutant-type OPG at this concentration had no cytotoxic effect on RAW264.7 cells.

The effect of $O P G$ gene mutation on osteoclast differentiation. RAW264.7 cells were induced by M-CSF + RANKL, while different concentrations of wild-type or mutant-type OPG were respectively added to the appropriate cells. After incubation for 4 days, there were multinuclear macrophages with characteristics of osteoclasts, such as being positive for TRAP. As shown in Fig. 3, the number of TRAP-positive cells decreased with increasing concentration of wild-type or mutant-type OPG. At the concentrations of 20,50 and $100 \mathrm{ng} / \mathrm{ml}$, the inhibitory effect of wild-type OPG was significantly higher than that of mutant-type OPG $(\mathrm{p}<0.05)$. These results demonstrate that the mutant-type OPG can affect the differentiation of osteoclasts.

The effect of $O P G$ gene mutation on bone resorption ability of osteoclasts. RAW264.7 cells were induced by M-CSF + 


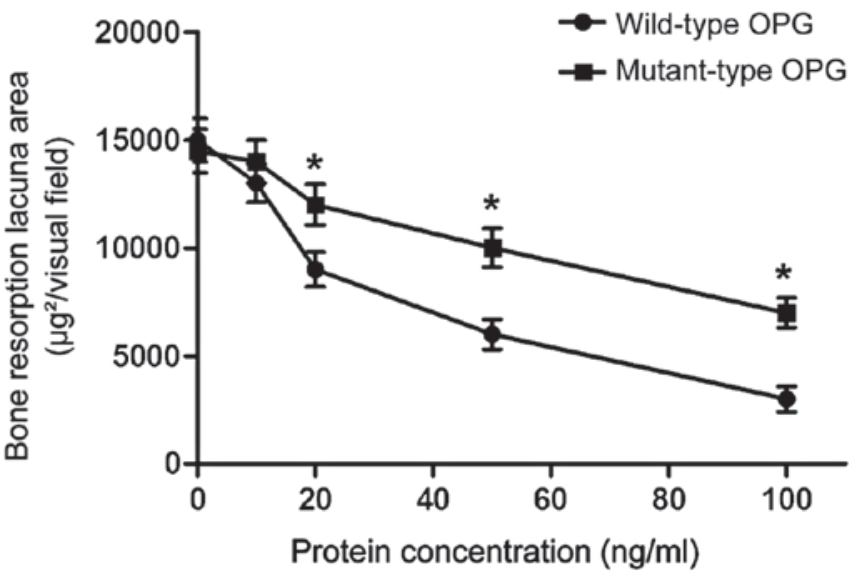

Figure 4. Inhibitory effect of OPG on osteoclast bone resorption activity. "Statistical significance when compared with the wild-type OPG group, $\mathrm{p}<0.05$. OPG, osteoprotegerin.

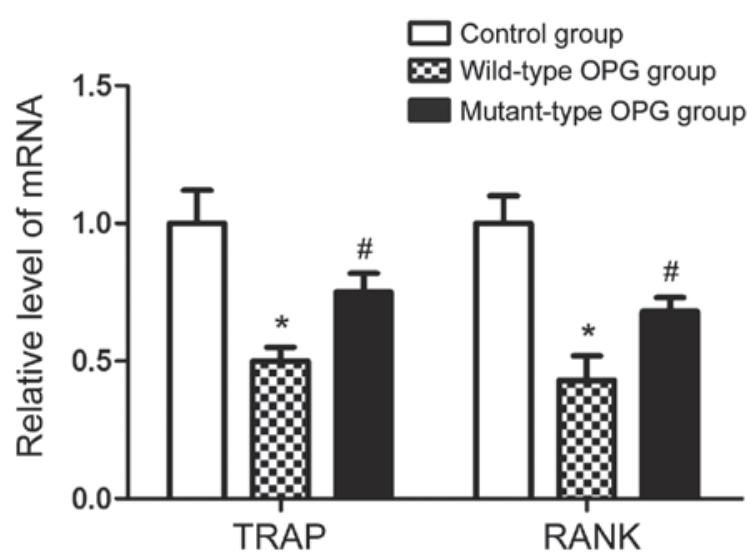

Figure 5. Effect of OPG on related mRNA expression levels. "'Statistical significance when compared with the control group, $\mathrm{p}<0.05$; ${ }^{\text {"Statistical }}$ significance when compared with the wild-type OPG group, $\mathrm{p}<0.05$. OPG, osteoprotegerin.

RANKL and differentiated into mature osteoclasts with bone resorption activity. Different concentrations of wild-type or mutant-type OPG were added respectively to each group. Various shapes of absorption lacuna appeared on bovine cortical bone slices. The smaller the area of resorption lacuna, the lower the bone resorption activity was. As shown in Fig. 4, both mutant-type and wild-type OPG inhibited the bone resorption activity of osteoclasts. The inhibitory effect of wild-type OPG was significantly higher than that of mutant-type OPG at the concentrations of 20,50 and $100 \mathrm{ng} / \mathrm{ml}(\mathrm{p}<0.05)$. These results indicate that mutant-type OPG can affect the bone resorption ability of osteoclasts.

The effect of OPG gene mutation on expression of genes related to osteoclast differentiation. RAW264.7 cells were treated with $100 \mathrm{ng} / \mathrm{ml}$ wild-type or mutant-type OPG. Next, the mRNA levels of the marker genes, TRAP and RANK, during the process of osteoclast differentiation were measured by RT-PCR. As shown in Fig. 5, the levels of TRAP and RANK mRNA in the wild-type OPG treatment group were significantly lower than those in the control group, while the levels of TRAP and RANK mRNA in the mutant-type OPG treatment group were significantly lower than those in the wild-type OPG treatment group $(\mathrm{p}<0.05)$. These results indicate that OPG gene mutation can affect osteoclast differentiation.

\section{Discussion}

Osteoporosis is a systemic bone disease that is characterized by decreased osteopenia and degeneration of the microstructure of bone tissues, thereby increasing bone fragility and the risk of fracture (6). Bone formation and bone resorption are the two basic processes of bone metabolism, and they are maintained in a dynamic balance. New bone is constantly being generated, while old bone is constantly being absorbed. Osteoclasts, which are a component of bone tissues, function in bone resorption. They exert a synergistic action with osteoblasts, which jointly play an important role in the process of bone development and formation. Both pathological increases and decreases of osteoclast activity can cause diseases, such as osteoporosis, bone sclerosis, and Paget disease. As a secreted glycoprotein, OPG is a member of the TNF receptor family, which exists as two forms, the monomer and homodimer $(7,8)$. A previous study showed that OPG gene knockout mice aged 1-2 months manifested severe osteoporosis and had complete absence of bone trabecula (9). Furthermore, the long bone, vertebra, and pelvis of transgenic mice with overexpression of OPG manifested obvious symptoms of bone sclerosis (10). We identified the genetic polymorphism, g.27563G $>$ A, within the fifth exon of the OPG gene by CRS-PCR. The female BMD associated with the GG genotype was significantly higher than that of the GA and AA genotypes. However, the specific association between OPG gene polymorphisms and osteoporosis remains unclear. Based on the successful establishment of the cell culture system with overexpression of the wild-type and mutant-type OPG gene, this study aimed to investigate the effect of the OPG gene mutation on its protein expression. The results indicated that the OPG gene mutation had no significant effect on its protein expression levels.

Osteoclast activation is the basis of bone resorption, and involves the transformation of mature osteoclasts in a resting state to an active state. This includes migration and adhesion to mineralized bone matrix, formation of the bone resorption microenvironment, and synthesis and secretion of a variety of functional enzymes. M-CSF and RANKL are two indispensable factors for osteoclast differentiation and activation. Under the combined action of M-CSF and RANKL, osteoclast precursors initially fuse to become osteoclasts, which are characterized by TRAP-positivity until they mature. Only by activation can mature osteoclasts acquire bone resorption activity. Hofbauer et al reported that OPG can regulate osteoclast differentiation, activation, and survival through the OPG-RANKL-RANK axis, thereby affecting skeletal metabolism in the body $(11,12)$. Therefore, whether the proteins encoded by the wild-type and mutant-type OPG genes act differently during differentiation and activation of osteoclasts requires further investigation. The results of this study showed that wild-type OPG inhibited the differentiation of osteoclasts, while the inhibitory effect of mutant-type OPG was significantly lower than that of the wild-type protein. However, the specific mechanism of action remains unclear and further research is needed. 
In conclusion, based on the successful establishment of a cell culture system with overexpression of the wild-type and mutant-type OPG gene, this study aimed to investigate the effect of an OPG gene mutation on its protein expression and activity. The results indicated that the genetic mutation did not affect the protein expression levels of OPG, but inhibited the normal activity of the OPG gene.

\section{References}

1. McCormick RK: Osteoporosis: Integrating biomarkers and other diagnostic correlates into the management of bone fragility. Altern Med Rev 12: 113-145, 2007.

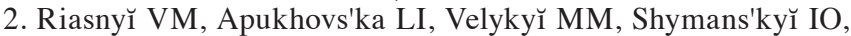
Labudzyns'kyı̌ DO and Komisarenko SV: Immunomodulatory effects of vitamin D3 and bisphosphonates in nutritional osteoporosis in rats. Ukr Biokhim Zh (1999) 84: 73-80, 2012 (In Ukrainian).

3. Hwang JS, Chen JF, Yang TS, Wu DJ, Tsai KS, Ho C, Wu CH, Su SL, Wang CJ and Tu ST: The effects of strontium ranelate in Asian women with postmenopausal osteoporosis. Calcif Tissue Int 83: 308-314, 2008

4. Hofbauer LC and Schoppet M: Osteoprotegerin gene polymorphism and the risk of osteoporosis and vascular disease. J Clin Endocrinol Metab 87: 4078-4079, 2002.
5. Ohmori H, Makita Y, Funamizu M, Hirooka K, Hosoi T, Orimo H, Suzuki T, Ikari K, Nakajima T, Inoue I, et al: Linkage and association analyses of the osteoprotegerin gene locus with human osteoporosis. J Hum Genet 47: 400-406, 2002.

6. Dominguez LJ, Scalisi R and Barbagallo M: Therapeutic options in osteoporosis. Acta Biomed 81 (Suppl 1): 55-65, 2010.

7. Montagnana M, Lippi G, Danese E and Guidi GC: The role of osteoprotegerin in cardiovascular disease. Ann Med 45: 254-264, 2013.

8. Brosch S, Redlich K and Pietschmann P: Pathogenesis of osteoporosis in rheumatoid arthritis. Acta Med Austriaca 30: 1-5, 2003 (In German).

9. Yasuda H, Shima N, Nakagawa N, Mochizuki SI, Yano K, Fujise N, Sato Y, Goto M, Yamaguchi K, Kuriyama M, et al: Identity of osteoclastogenesis inhibitory factor (OCIF) and osteoprotegerin (OPG): A mechanism by which OPG/OCIF inhibits osteoclastogenesis in vitro. Endocrinology 139: 1329-1337, 1998.

10. Wright HL, McCarthy HS, Middleton J and Marshall MJ: RANK, RANKL and osteoprotegerin in bone biology and disease. Curr Rev Musculoskelet Med 2: 56-64, 2009.

11. Hofbauer LC, Kühne CA and Viereck V: The OPG/RANKL/ RANK system in metabolic bone diseases. J Musculoskelet Neuronal Interact 4: 268-275, 2004.

12. Khosla S: Minireview: The OPG/RANKL/RANK system. Endocrinology 142: 5050-5055, 2001. 